\title{
A Diversity of Cell Types, Subtypes and Phenotypes in the Central Nervous System: The Importance of Studying Their Complex Relationships
}

\author{
Marie-Ève Tremblay ${ }^{1,2,3,4,5 *}$ \\ 'Axe Neurosciences, Centre de recherche du CHU de Québec - Université Laval, Québec, QC, Canada, ${ }^{2}$ Département de \\ Médecine Moléculaire, Université Laval, Québec, QC, Canada, ${ }^{3}$ Department of Neurology and Neurosurgery, McGill \\ University, Montréal, QC, Canada, ${ }^{4}$ Division of Medical Sciences, University of Victoria, Victoria, BC, Canada, ${ }^{5}$ Department \\ of Biochemistry and Molecular Biology, Faculty of Medicine, The University of British Colombia, Vancouver, BC, Canada
}

Keywords: microglia, astrocyte, oligodendrocyte lineage cell, peripheral immune cell, subtypes, diversity, interactions, CNS

\section{OPEN ACCESS}

Edited and reviewed by: Christian Hansel,

University of Chicago, United States

*Correspondence: Marie-Ëve Tremblay evetremblay@uvic.ca

Specialty section: This article was submitted to Non-Neuronal Cells,

a section of the journal

Frontiers in Cellular Neuroscience

Received: 11 November 2020 Accepted: 13 November 2020 Published: 23 December 2020

Citation:

Tremblay M-È (2020) A Diversity of Cell Types, Subtypes and Phenotypes in the Central Nervous System: The Importance of Studying Their Complex

Relationships.

Front. Cell. Neurosci. 14:628347.

doi: $10.3389 /$ fncel.2020.628347
All the cell types in the central nervous system (CNS) cooperate to mediate proper development, function, and plasticity. Similarly, brain repair and neuroprotection, but also demyelination, synaptic loss and neurodegeneration, were increasingly shown to involve non-neuronal cellsboth glial cells and peripheral immune cells-among the CNS parenchyma. Adding another degree of complexity, the non-neuronal cell populations are emerging as comprised of different subtypes, endowed with unique properties and functions at steady-state, and which can adopt various phenotypes upon exposure to homeostatic challenges. As a consequence, studying the multidirectional relationships between these different cell types, subtypes and phenotypes in the CNS is now required to provide insights into the mechanisms underlying physiological processes such as neuronogenesis, axon guidance, myelination, vascular formation and remodeling, regulation of neuronal activity, as well as synaptic formation, function and plasticity, and behavioral outputs, among other essential CNS functions.

\section{A DIVERSITY OF CELL TYPES, SUBTYPES, AND PHENOTYPES}

In the CNS, the different types of neurons, which are identified by their neurotransmitters, neurotrophic or neuroprotective factors (Que et al., 2019; Sugino et al., 2019; Cizeron et al., 2020), are accompanied by non-neuronal cells showing similar, or greater levels of heterogeneity. This cellular diversity pertains to glial cells (microglia, astrocytes, cells of the oligodendrocytic lineage) and the peripheral immune cells that can infiltrate the CNS (Oberheim et al., 2012; Butt and Verkhratsky, 2018; Foerster et al., 2019; Stratoulias et al., 2019; Dumas and Prinz, 2020). While the microglial field rejected the M1 and M2 categorization (Martinez and Gordon, 2014; Ransohoff, 2016), the A1 and A1 astrocytic dichotomy is increasingly controversial (Oberheim et al., 2012; Verkhratsky and Nedergaard, 2018; Khakh and Deneen, 2019; Westergard and Rothstein, 2020). Cells of the oligodendrocytic lineage are also emerging as a diverse population with different subsets co-existing among the CNS (Foerster et al., 2019). Similarly, peripheral immune cells comprised of granulocytes (neutrophils, eosinophils, and basophils), monocytes, and lymphocytes (T cells and B cells) are highly heterogeneous, and accompanied by additional CNS border-associated populations, yet the nature of the cells infiltrating the CNS, and their distinctive properties once 
in the CNS environment are less understood (Theret et al., 2019; Dumas and Prinz, 2020). Accumulating findings reveal that glial and peripheral immune cells display distinct subsets that vary in their localization, epigenetic signature, protein and gene expression, but also in their morphological and ultrastructural attributes (Bisht et al., 2016; Ayata et al., 2018; Silvin and Ginhoux, 2018; Foerster et al., 2019; Khakh and Deneen, 2019; Stratoulias et al., 2019; Burns et al., 2020; Castellani and Schwartz, 2020; St-Pierre et al., 2020; Tan et al., 2020; Westergard and Rothstein, 2020). Whether the non-neuronal subsets in the CNS indicate the existence of different subtypes, with unique intrinsic properties and specialized functions, or reflect phenotypes that change their properties and functions upon exposure to challenges, or both, remains in most cases elusive. Understanding how the glial and peripheral immune cell heterogeneity determines varied functions in the CNS, at steadystate and upon various challenges, is importantly required to design cellular interventions that specifically target (modulate, stimulate or inhibit) microglia, astrocytes, oligodendrocytic lineage cells or peripheral immune cells performing contextuallydesirable or undesirable functions.

\section{THE CHALLENGE OF STUDYING THEIR COMPLEX RELATIONSHIPS}

Distinguishing between glial and immune cell subtypes and phenotypes in the CNS requires fate mapping tools that allow to follow individual cells over time. Such approaches, which are becoming increasingly available, have been used by pioneering investigations to determine the origin of tissue resident macrophages, including microglia (Prinz et al., 2014; Perdiguero and Geissmann, 2016), or the turnover and longevity of microglia within the CNS (Askew et al., 2017; Füger et al., 2017; Tay et al., 2017b), among other important findings. To complement the fate mapping strategies, in situ and in vivo approaches should be prioritized to study the biological relevance of glial and immune diversity in the CNS, considering that in vitro and ex vivo preparations modify non-neuronal cell responses (Hellwig et al., 2013; Gosselin et al., 2014). Recent technological advances such as single cell transcriptome analysis have revealed an unprecedented heterogeneity in the nonneuronal cells of the CNS's molecular signatures (Krasemann et al., 2017; Hammond et al., 2019; Kierdorf et al., 2019; Deczkowska et al., 2020). Nevertheless, whether the glial and immune cells in the CNS are multitasking or perform specialized functions still remains largely undetermined. Considering that essential CNS functions emerge from the dynamic interactions between all cell types in the CNS, including learning and memory, judgement, emotional transformation, decision making, as well as behavioral outputs, it would be essential to unravel the complex relationships between cell types, subtypes, and phenotypes of neuronal and non-neuronal cells in the CNS. The neurons, microglia, astrocytes, and oligodendrocytic lineage cells have been shown to interact with another, structurally and functionally, and they communicate with the peripheral leukocytes infiltrating the CNS or transiting via the perivascular space and other CNS borders (Neuroimmune Communication, 2017; Tay et al., 2017c; Carrier et al., 2020). Microglia can control astrocytic functions, and vice versa, astrocytes can influence microglia, and the same holds for the reciprocal crosstalks taking place between astrocytes, microglia, and oligodendrocytic lineage cells (Béchade et al., 2013; Kettenmann et al., 2013; Domingues et al., 2016; Liddelow et al., 2017; Matejuk and Ransohoff, 2020). Within this integrative viewpoint, collaborative research endeavors that bridge complementary expertise with the different non-neuronal cell types, subtypes and phenotypes, are now required to provide maximal insights into the functional relevance of these multidimensional relationships within the CNS.

\section{THE INDIVIDUAL CIRCUMSTANCES INCREASING VARIABILITY}

Non-neuronal cell types, subtypes and phenotypes vary between CNS regions, stages of life, sex, specie, and context of health or disease (Silvin and Ginhoux, 2018; Foerster et al., 2019; Khakh and Deneen, 2019; Stratoulias et al., 2019; Castellani and Schwartz, 2020; Tan et al., 2020; Westergard and Rothstein, 2020). Their diversity is modulated by the genetic vulnerabilities, environmental challenges (e.g., stress, infection, pollution), lifestyle factors (e.g., diet, sleep, physical activity, alcohol, cannabis), peripheral comorbidities (e.g., asthma, colitis, arthritis) and other individual circumstances (e.g., exposure to nature, social support), thus tremendously increasing the variability (Hanamsagar and Bilbo, 2017; Tay et al., 2017a; Savage and Tremblay, 2019; Madore et al., 2020). The non-neuronal cells further display differences in their CNS colonization, maturation, gene and protein expression, morphology, ultrastructure, function, and response to challenges between the sexes (Schwarz and Bilbo, 2012; Hui St.-Pierre et al., 2018; Nelson et al., 2019; Bordeleau et al., 2020; Yasuda et al., 2020). In the periphery, the concept of "immunobiography" has been formulated, to reflect the tremendous inter-individual differences in immune function cumulating during life, and propose the idea that the individual immune signature can inform in a very sensitive manner on the state of health or disease, and allow to predict the outcome of various treatment strategies (Del Giudice et al., 2017; Franceschi et al., 2017). Similarly, the physiological and immune functions of both microglia and astrocytes are regulated by a multitude of external influences, which can induce cellular memory and epigenetic remodeling (Reemst et al., 2016; Valero et al., 2016; Tay et al., 2017a; Ayata et al., 2018; Murphy-Royal et al., 2019; Wheeler et al., 2019; Madore et al., 2020). As a consequence, elucidating how various individual circumstances guide the multidimensional relationships between neuronal and non-neuronal cell types, subtypes and phenotypes in the CNS, is expected to provide unprecedented opportunities to develop personalized treatment strategies for a wide variety of neurodevelopmental, neuropsychiatric and neurodegenerative diseases in which the neuronal and non-neuronal cells of the CNS are together critically involved. 


\section{AUTHOR CONTRIBUTIONS}

The author confirms being the sole contributor of this work and has approved it for publication.

\section{REFERENCES}

Askew, K., Li, K., Olmos-Alonso, A., Garcia-Moreno, F., Liang, Y., Richardson, P., et al. (2017). Coupled proliferation and apoptosis maintain the rapid turnover of microglia in the adult brain. Cell Rep. 18, 391-405. doi: 10.1016/j.celrep.2016.12.041

Ayata, P., Badimon, A., Strasburger, H. J., Duff, M. K., Montgomery, S. E., Loh, Y.-H. E., et al. (2018). Epigenetic regulation of brain regionspecific microglia clearance activity. Nature Neurosci. 21, 1049-1060. doi: 10.1038/s41593-018-0192-3

Béchade, C., Cantaut-Belarif, Y., and Bessis, A. (2013). Microglial control of neuronal activity. Front. Cell. Neurosci. 7:32. doi: 10.3389/fncel.2013.00032

Bisht, K., Sharma, K. P., Lecours, C., Sánchez, M. G., El Hajj, H., Milior, G., et al. (2016). Dark microglia: a new phenotype predominantly associated with pathological states. Glia 64, 826-839. doi: 10.1002/glia. 22966

Bordeleau, M., Lacabanne, C., Fernández de Cossío, L., Vernoux, N., Savage, J. C., González-Ibáñez, F., et al. (2020). Microglial and peripheral immune priming is partially sexually dimorphic in adolescent mouse offspring exposed to maternal high-fat diet. J. Neuroinflamm. 17:264. doi: 10.1186/s12974-02 0-01914-1

Burns, J. C., Cotleur, B., Walther, D. M., Bajrami, B., Rubino, S. J., Wei, R., et al. (2020). Differential accumulation of storage bodies with aging defines discrete subsets of microglia in the healthy brain. Elife 9:e57495. doi: 10.7554/eLife.57495.sa2

Butt, A., and Verkhratsky, A. (2018). Neuroglia: realising their true potential. Brain Neurosci. Adv. 2, 208-215. doi: 10.1177/2398212818817495

Carrier, M., Robert, M.-Ẽ., González Ibáñez, F., Desjardins, M., and Tremblay, M.E. (2020). Imaging the neuroimmune dynamics across space and time. Front. Neurosci. 14:903. doi: 10.3389/fnins.2020.00903

Castellani, G., and Schwartz, M. (2020). Immunological features of non-neuronal brain cells: implications for Alzheimer's Disease immunotherapy. Trends Immunol. 41, 794-804. doi: 10.1016/j.it.2020.07.005

Cizeron, M., Qiu, Z., Koniaris, B., Gokhale, R., Komiyama, N. H., Fransén, E., et al. (2020). A brain-wide atlas of synapses across the mouse lifespan. Science 369, 270-275. doi: 10.1126/science.aba3163

Deczkowska, A., Weiner, A., and Amit, I. (2020). The physiology, pathology, and potential therapeutic applications of the TREM2 signaling pathway. Cell 181, 1207-1217. doi: 10.1016/j.cell.2020.05.003

Del Giudice, G., Goronzy, J. J., Grubeck-Loebenstein, B., Lambert, P.-H., Mrkvan, T., Stoddard, J. J., et al. (2017). Fighting against a protean enemy: immunosenescence, vaccines, and healthy aging. npj Aging Mech. Dis. 4, 1-8. doi: 10.1038/s41514-017-0020-0

Domingues, H. S., Portugal, C. C., Socodato, R., and Relvas, J. B. (2016). Oligodendrocyte, astrocyte, and microglia crosstalk in myelin development, damage, and repair. Front. Cell Dev. Biol. 4:79. doi: 10.3389/fcell.2016. 00079

Dumas, A. A., and Prinz, M. (2020). The myeloid side of the CNS. Brain Pathol. e12907. doi: 10.1111/bpa.12907. [Epub ahead of print].

Foerster, S., Hill, M. F. E., and Franklin, R. J. M. (2019). Diversity in the oligodendrocyte lineage: plasticity or heterogeneity? Glia 67, 1797-1805. doi: 10.1002/glia.23607

Franceschi, C., Salvioli, S., Garagnani, P., de Eguileor, M., Monti, D., and Capri, M. (2017). Immunobiography and the heterogeneity of immune responses in the elderly: a focus on inflammaging and trained immunity. Front. Immunol. 8:982. doi: 10.3389/fimmu.2017.00982

Füger, P., Hefendehl, J. K., Veeraraghavalu, K., Wendeln, A.-C., Schlosser, C., Obermüller, U., et al. (2017). Microglia turnover with aging and in an Alzheimer's model via long-term in vivo single-cell imaging. Nat. Neurosci. 20, 1371-1376. doi: 10.1038/nn.4631

\section{ACKNOWLEDGMENTS}

M-ÈT is a Canada Research Chair Tier II in Neurobiology of Aging and Cognition.

Gosselin, D., Link, V. M., Romanoski, C. E., Fonseca, G. J., Eichenfield, D Z., Spann, N. J., et al. (2014). Environment drives selection and function of enhancers controlling tissue-specific macrophage identities. Cell 159, 1327-1340. doi: 10.1016/j.cell.2014.11.023

Hammond, T. R., Dufort, C., Dissing-Olesen, L., Giera, S., Young, A., Wysoker, A., et al. (2019). Single-cell RNA sequencing of microglia throughout the mouse lifespan and in the injured brain reveals complex cell-state changes. Immunity 50, 253-271.e6. doi: 10.1016/j.immuni.2018.11.004

Hanamsagar, R., and Bilbo, S. D. (2017). Environment matters: microglia function and dysfunction in a changing world. Curr. Opin. Neurobiol. 47, 146-155. doi: 10.1016/j.conb.2017.10.007

Hellwig, S., Heinrich, A., and Biber, K. (2013). The brain's best friend: microglial neurotoxicity revisited. Front. Cell. Neurosci. 7:71. doi: 10.3389/fncel.2013.00071

Hui St.-Pierre, A., El Hajj, H., Remy, Y., Hébert, S. S., Luheshi, G. N., et al. (2018). Prenatal immune challenge in mice leads to partly sex-dependent behavioral, microglial, and molecular abnormalities associated with schizophrenia. Front. Mol. Neurosci. 11:13. doi: 10.3389/fnmol.2018.00013

Kettenmann, H., Kirchhoff, F., and Verkhratsky, A. (2013). Microglia: new roles for the synaptic stripper. Neuron 77, 10-18. doi: 10.1016/j.neuron.2012.12.023

Khakh, B. S., and Deneen, B. (2019). The emerging nature of astrocyte diversity. Ann. Rev. Neurosci. 42, 187-207. doi: 10.1146/annurev-neuro-070918-050443

Kierdorf, K., Masuda, T., Jordão, M. J. C., and Prinz, M. (2019). Macrophages at CNS interfaces: ontogeny and function in health and disease. Nat. Rev. Neurosci. 20, 547-562. doi: 10.1038/s41583-019-0201-x

Krasemann, S., Madore, C., Cialic, R., Baufeld, C., Calcagno, N., El Fatimy, R., et al. (2017). The TREM2-APOE pathway drives the transcriptional phenotype of dysfunctional microglia in neurodegenerative diseases. Immunity 47, 566-581.e9. doi: 10.1016/j.immuni.2017.08.008

Liddelow, S. A., Guttenplan, K. A., Clarke, L. E., Bennett, F. C., Bohlen, C. J., Schirmer, L., et al. (2017). Neurotoxic reactive astrocytes are induced by activated microglia. Nature 541, 481-487. doi: 10.1038/nature21029

Madore, C., Yin, Z., Leibowitz, J., and Butovsky, O. (2020). Microglia, lifestyle stress, and neurodegeneration. Immunity 52, 222-240. doi: 10.1016/j.immuni.2019.12.003

Martinez, F. O., and Gordon, S. (2014). The M1 and M2 paradigm of macrophage activation: time for reassessment. F1000Prime Rep 6:13. doi: 10.12703/P6-13

Matejuk, A., and Ransohoff, R. M. (2020). Crosstalk between astrocytes and microglia: an overview. Front. Immunol. 11:1416. doi: 10.3389 /fimmu.2020.01416

Murphy-Royal, C., Gordon, G. R., and Bains, J. S. (2019). Stress-induced structural and functional modifications of astrocytes-Further implicating glia in the central response to stress. Glia 67, 1806-1820. doi: 10.1002/glia.23610

Nelson, L. H., Saulsbery, A. I., and Lenz, K. M. (2019). Small cells with big implications: microglia and sex differences in brain development, plasticity and behavioral health. Prog. Neurobiol. 176, 103-119. doi: 10.1016/j.pneurobio.2018.09.002

Neuroimmune Communication (2017). Nat. Immunol. 18:115. doi: 10.1038/ni.3676

Oberheim, N. A., Goldman, S. A., and Nedergaard, M. (2012). Heterogeneity of astrocytic form and function. Methods Mol. Biol. 814, 23-45. doi: 10.1007/978-1-61779-452-0_3

Perdiguero, E. G., and Geissmann, F. (2016). The development and maintenance of resident macrophages. Nat. Immunol. 17, 2-8. doi: 10.1038/ni.3341

Prinz, M., Tay, T. L., Wolf, Y., and Jung, S. (2014). Microglia: unique and common features with other tissue macrophages. Acta Neuropathol. 128, 319-331. doi: 10.1007/s00401-014-1267-1

Que, L., Winterer, J., and Földy, C. (2019). Deep survey of GABAergic interneurons: emerging insights from gene-isoform transcriptomics. Front. Mol. Neurosci. 12:115. doi: 10.3389/fnmol.2019.00115 
Ransohoff, R. M. (2016). A polarizing question: do M1 and M2 microglia exist? Nat. Neurosci. 19, 987-991. doi: 10.1038/nn.4338

Reemst, K., Noctor, S. C., Lucassen, P. J., and Hol, E. M. (2016). The indispensable roles of microglia and astrocytes during brain development. Front. Hum. Neurosci. 10:566. doi: 10.3389/fnhum.2016.00566

Savage, J. C., and Tremblay, M.-E. (2019). Studying laboratory mice - into the wild. Trends Neurosci. 42, 566-568. doi: 10.1016/j.tins.2019.05.004

Schwarz, J. M., and Bilbo, S. D. (2012). Sex, glia, and development: interactions in health and disease. Horm. Behav. 62, 243-253. doi: 10.1016/j.yhbeh.2012.02.018

Silvin, A., and Ginhoux, F. (2018). Microglia heterogeneity along a spatio-temporal axis: More questions than answers. Glia 66, 2045-2057. doi: 10.1002/glia.23458

St-Pierre, M.-K., Šimončičová, E., Bögi, E., and Tremblay, M.-Ë. (2020). Shedding light on the dark side of the microglia. ASN Neuro 12:1759091420925335. doi: $10.1177 / 1759091420925335$

Stratoulias, V., Venero, J. L., Tremblay, M.-Ë., and Joseph, B. (2019). Microglial subtypes: diversity within the microglial community. EMBO J. 38:e101997. doi: $10.15252 / \mathrm{embj} .2019101997$

Sugino, K., Clark, E., Schulmann, A., Shima, Y., Wang, L., Hunt, D. L., et al. (2019). Mapping the transcriptional diversity of genetically and anatomically defined cell populations in the mouse brain. eLife 8:e38619. doi: $10.7554 /$ eLife.38619.048

Tan, Y.-L., Yuan, Y., and Tian, L. (2020). Microglial regional heterogeneity and its role in the brain. Mol. Psychiatry 25, 351-367. doi: 10.1038/s41380-019-0609-8

Tay, T. L., Béchade, C., D’Andrea, I., St-Pierre, M.-K., Henry, M. S., Roumier, A., et al. (2017a). Microglia gone rogue: impacts on psychiatric disorders across the lifespan. Front. Mol. Neurosci. 10:421. doi: 10.3389/fnmol.2017.00421

Tay, T. L., Mai, D., Dautzenberg, J., Fernández-Klett, F., and Lin, G., Sagar, null, et al. (2017b). A new fate mapping system reveals context-dependent random or clonal expansion of microglia. Nat. Neurosci. 20, 793-803. doi: 10.1038/nn.4547

Tay, T. L., Savage, J. C., Hui, C. W., Bisht, K., and Tremblay, M.-È. (2017c). Microglia across the lifespan: from origin to function in brain development, plasticity and cognition. J. Physiol. 595, 1929-1945. doi: 10.1113/ JP272134

Theret, M., Mounier, R., and Rossi, F. (2019). The origins and non-canonical functions of macrophages in development and regeneration. Development 146:dev156000. doi: 10.1242/dev.156000

Valero, J., Paris, I., and Sierra, A. (2016). Lifestyle shapes the dialogue between environment, microglia, and adult neurogenesis. ACS Chem. Neurosci. 7, 442-453. doi: 10.1021/acschemneuro.6b00009

Verkhratsky, A., and Nedergaard, M. (2018). Physiology of Astroglia. Physiol. Rev. 98, 239-389. doi: 10.1152/physrev.00042.2016

Westergard, T., and Rothstein, J. D. (2020). Astrocyte diversity: current insights and future directions. Neurochem. Res. 45, 1298-1305. doi: 10.1007/s11064-020-02959-7

Wheeler, M. A., Jaronen, M., Covacu, R., Zandee, S. E. J., Scalisi, G., Rothhammer, V., et al. (2019). Environmental control of astrocyte pathogenic activities in CNS inflammation. Cell 176, 581-596.e18. doi: 10.1016/j.cell.2018.12.012

Yasuda, K., Maki, T., Kinoshita, H., Kaji, S., Toyokawa, M., Nishigori, R., et al. (2020). Sex-specific differences in transcriptomic profiles and cellular characteristics of oligodendrocyte precursor cells. Stem Cell Res. 46:101866. doi: 10.1016/j.scr.2020.101866

Conflict of Interest: The author declares that the research was conducted in the absence of any commercial or financial relationships that could be construed as a potential conflict of interest.

Copyright $\odot 2020$ Tremblay. This is an open-access article distributed under the terms of the Creative Commons Attribution License (CC BY). The use, distribution or reproduction in other forums is permitted, provided the original author $(s)$ and the copyright owner(s) are credited and that the original publication in this journal is cited, in accordance with accepted academic practice. No use, distribution or reproduction is permitted which does not comply with these terms. 